\title{
Determinantes do Intercâmbio Comercial de Produtos Agrícolas entre Brasil e China: o Caso da Soja
}

\section{Determinants of Trade Flows of Agricultural Products between Brazil and China: the Case of Soy}

\author{
Paulo Ricardo Feistel* \\ Álvaro Barrantes Hidalgo** \\ Fernando Bitencourt Zuchetto***
}

Resumo: Este trabalho tem por objetivo analisar os principais determinantes das exportações agrícolas brasileiras para a China, em particular, da soja, que representaram em média $86,0 \%$ das exportações do Brasil para o mercado chinês no período de março de 2001 a março de 2009. A China é um dos países que mais elevaram as importações agrícolas nos últimos anos, importando cerca de $53,7 \%$ da soja mundial entre 2001 e 2009, enquanto que, no mesmo período, o Brasil foi o segundo maior produtor mundial, com quase 30,0\% da produção e 37,0\% das exportações mundiais. Neste trabalho, além da renda chinesa, são consideradas as variáveis preço das exportações de soja e taxa de câmbio real. O procedimento empregado é o método de cointegração de Johansen, que aponta para a existência de relações de longo prazo entre o preço e a renda, cujas alterações ao longo do tempo tornaram as exportações de soja para a China relativamente estáveis no intervalo estudado. Constata-se também que modificações de curto prazo nas variáveis abordadas levam ao desequilíbrio momentâneo entre preço e renda, porém com tais discrepâncias sendo corrigidas nos períodos posteriores. As elasticidades obtidas parecem evidenciar que o volume de exportação de soja para a China é significativamente afetado pelo nível de renda do país e, em menor proporção, pela taxa de câmbio real.

Palavras-chave: Soja. Comércio. Brasil. China.

\begin{abstract}
This paper aims at analyzing the main determinants of Brazilian agricultural exports to China, in particular, the soybeans that represented on average $86.0 \%$ of Brazil's exports to the Chinese market between March 2001 and March 2009. China is one of the countries that increased agricultural imports in recent years importing about $53.7 \%$ of world soybean between 2001 and 2009, while during the same period Brazil was the second largest producer in the world with almost $30.0 \%$ of production and $37.0 \%$ of world exports. In this work, besides the Chinese income, were considered variables:

* Doutor em Economia pelo Programa de Pós-Graduação em Economia (PIMES) da Universidade Federal de Pernambuco (UFPE). Professor do Programa de Pós-Graduação em Economia e Desenvolvimento (PPGEED) e do Departamento de Economia da Universidade Federal de Santa Maria (UFSM). E-mail: prfeistel@yahoo.com.br

* $\quad$ Doutor em Economia pela Universidade de São Paulo (USP). Professor do Programa de Pós-Graduação em Economia (PIMES) da Universidade Federal de Pernambuco (UFPE). Pesquisador do CNPq. E-mail: abarrantes@uol.com.br

** Mestrando pelo Programa de Pós-Graduação em Economia (PPGE) da Universidade Federal do Rio Grande do Sul (UFRGS). E-mail: fernandobzucheto@hotmail.com
\end{abstract}


price of soybean exports and real exchange rate. The procedure used was the method of Johansen co-integration which pointed to the existence of long-term relationships between price and income, whose changes over time became soybean exports to China relatively stable in the range studied. It was also found that short-term changes in the variables addressed lead to momentary imbalance between price and income; such discrepancies were corrected in subsequent periods. The elasticities obtained seem to indicate that the volume of soybean exports to China is significantly affected by the level of income in that country and to a lesser extent by the real exchange rate.

Keywords: Soy. Trade. Brazil. China.

JEL Classification: Q17.

\section{1 lntrodução}

O crescimento econômico da economia chinesa nas últimas décadas tem sido acompanhado pelo aumento da importação de bens intensivos em recursos naturais, produtos que são importantes para a sustentação da produção industrial chinesa. Aliada à expansão industrial, a China vem passando por um processo de urbanização e aumento de renda que tem levado à necessidade de importação de alimentos, a fim de suprir a crescente demanda interna. Assim, países bem dotados de recursos naturais, como é o caso do Brasil, vêm aprofundando suas relações comerciais com a China. O Brasil, um dos maiores produtores de carne e grãos do mundo, surge como um dos países que vem suprir esse mercado, exportando para a China principalmente produtos primários, entre eles destaca-se a soja. ${ }^{1}$

A China é um dos países que mais elevaram as importações agrícolas nos últimos anos, com taxa média anual de crescimento das importações de 20,2\%, destacando-se, assim, como o maior importador de soja do mundo, importando 53,7\% da soja mundial em 2009. Apesar disso, segundo dados do Ministério da Agricultura, o Brasil surge nos últimos anos como o segundo maior exportador de soja do mundo, com média de 37,0\% das exportações mundiais durante o período de 2001 a 2009, sendo que cerca de 30,0\% da produção mundial também é brasileira. Isso cria a necessidade de importações chinesas de soja produzida no

1 A pauta de exportação brasileira é caracterizada pelo conteúdo de produtos primários. Durante o período de 2001 a 2009, mercadorias providas da extração mineral/vegetal e da produção agrícola estiveram entre as mais vendidas para o exterior. Segundo dados disponíveis no site do Ministério da Agricultura, petróleo (óleo bruto), açúcar de cana (bruto), café (grão), minério de ferro (aglomerado e não aglomerado) e soja (grão e farelo e resíduos da extração do óleo) mantiveram-se entre os dez principais produtos exportados nos oito anos em questão. Dentre esses produtos, destaca-se a soja em grão ou em farelo (triturada), que representou em média 5\% do total exportado pelo Brasil no período 2001-2008. Durante esse período, a soja foi a mercadoria com maior peso individual nas vendas externas brasileiras. Considerando-se, em particular, "o complexo soja" na totalidade de bens exportados relacionados à oleaginosa, evidencia-se novamente a importância da soja em grão ou em farelo e que em 2008 foi responsável por 60,73\% do todo, sendo que em nenhum ano, entre 2001 e 2009, ficou abaixo de $50 \%$ do total. 
Brasil. Essas características justificam que cerca de 35\% das compras chinesas da oleaginosa sejam realizadas de produtores brasileiros. ${ }^{2}$

Levando em consideração o total que Brasil exportou para a China em 2008, em torno de $32,46 \%$ consistiam em soja em grão ou triturada. ${ }^{3}$ Por outro lado, fazendo o cruzamento entre os produtos brasileiros exportados e os respectivos destinos, pode-se constatar que a soja (triturada e em grão) remetida para a China no ano de 2008 correspondia a 2,69\% de tudo o que o Brasil vendeu para o exterior nesse ano. Portanto, considerando tanto os bens comercializados no exterior, quanto as nações para onde são enviados esses produtos, temos a soja (em grão e triturada) remetida para a China como um dos mais importantes.

Assim, a crescente importância das relações comerciais entre o Brasil e a China, em especial a comercialização de soja, justifica a realização deste trabalho, cujo objetivo principal consiste em identificar quais são os fatores que influenciam as exportações brasileiras de soja para esse mercado. A fim de atingir esse objetivo, foi utilizada uma abordagem econométrica procurando analisar quais são as variáveis mais significativas que explicam a quantidade exportada de soja do Brasil para a China. Utilizando a teoria econômica sobre determinantes do comércio, procurou-se identificar quais são os possíveis fatores que explicam as exportações de soja do Brasil para a China. O estudo dessa questão é importante não apenas para conhecer melhor os determinantes das exportações de soja brasileira para a China, mas também como subsídio para a formulação de políticas para o setor. A estimação de modelo econométrico da demanda de exportações é relevante, tendo em vista que a formulação de estratégias de inserção internacional para a economia torna necessário conhecer ex ante os prováveis efeitos de mudanças nas variáveis sobre o volume exportado. O conhecimento das elasticidades da demanda de exportação é um poderoso instrumento que permite fazer previsões, resultantes de mudanças na política econômica ou de choques exógenos, sobre o comportamento das exportações do setor. O comércio internacional da soja tem sido objeto de estudo por parte de diversos autores, entretanto há poucos estudos específicos sobre o comércio Brasil-China dessa mercadoria. ${ }^{4}$

2 Dados elaborados a partir de informações disponíveis no site da Food and Agriculture Organization of the United Nations.

3 As informações a respeito das exportações brasileiras por mercadoria e país de destino foram coletadas ou elaboradas com base em dados disponíveis no site do Ministério do Desenvolvimento Indústria e Comércio (MDIC), sistema Aliceweb (BRASIL, 2007).

4 Entre os trabalhos que analisam o mercado internacional da soja, cabe destacar: Sampaio, Sampaio e Costa (2006), os quais, utilizando um modelo de equilíbrio geral, analisam as políticas recentes, a competitividade e as perspectivas no mercado internacional da soja; Brandão e Lima (2006), que estimam um modelo econométrico do mercado de soja e derivados com o objetivo de avaliar os efeitos das políticas de apoio interno dos Estados Unidos sobre os preços internacionais, produção e exportações de soja; Souza et al. (2007), que, por sua vez, analisam os efeitos da taxa de câmbio, da quantidade exportada e do preço internacional da soja sobre a receita de exportação dessa mercadoria no período de 1994 a 2005. A análise foi feita através do método shift-share, o qual permite verificar o efeito isolado de cada uma das variáveis estudadas sobre 
A fim de se atingir o objetivo, o artigo se divide em cinco seções: na seção 2 é apresentada uma análise das mudanças acontecidas na estrutura do comércio exterior brasileiro com a China durante o período pós-abertura comercial; na seção 3 é exposto o método utilizado para conhecer melhor os determinantes das exportações brasileiras de soja para a China; na seção 4 é realizada a análise dos resultados obtidos; e na seção 5 são apresentadas as considerações finais do trabalho.

\section{A Estrutura do Intercâmbio Comercial entre o Brasil e a China}

A fim de conhecer melhor as mudanças acontecidas na estrutura do comércio exterior brasileiro com a China no período recente, neste trabalho foram agrupados os produtos que participam do comércio entre os dois países em 14 grupos de produtos. ${ }^{5}$ Assim, na Tabela 1 é apresentada a estrutura das exportações e importações brasileiras para o período de 1992 a 2009.

a referida receita; Figueiredo, Santos e Lirio (2004a), que estimam e analisam a elasticidade de substituição entre Brasil, Estados Unidos e Argentina nas exportações de soja em grão, em mercados importadores selecionados e procuram verificar a possibilidade de substituição entre as exportações de soja em grão do Brasil, Estados Unidos e Argentina; Figueiredo, Santos e Lirio (2004b), que analisam os fatores que explicam a alteração da participação da agroindústria brasileira de soja no comércio internacional e discutem a competitividade do Brasil nas exportações de cada segmento da agroindústria de soja; Carvalho, Silva e Ghilardi (2005), que, utilizando um conjunto de indicadores, analisam a competitividade da soja brasileira e sua capacidade para gerar divisas; e Coronel, Machado e Carvalho (2009), que tentam identificar as principais fontes de crescimento das exportações brasileiras do complexo soja de 1995 a 2006 com base no modelo constant-market-share.

5 O critério de agrupamento dos produtos segue de perto o sugerido por Thorstensen et al. (1994), muito utilizado em diversos trabalhos sobre comércio exterior. 


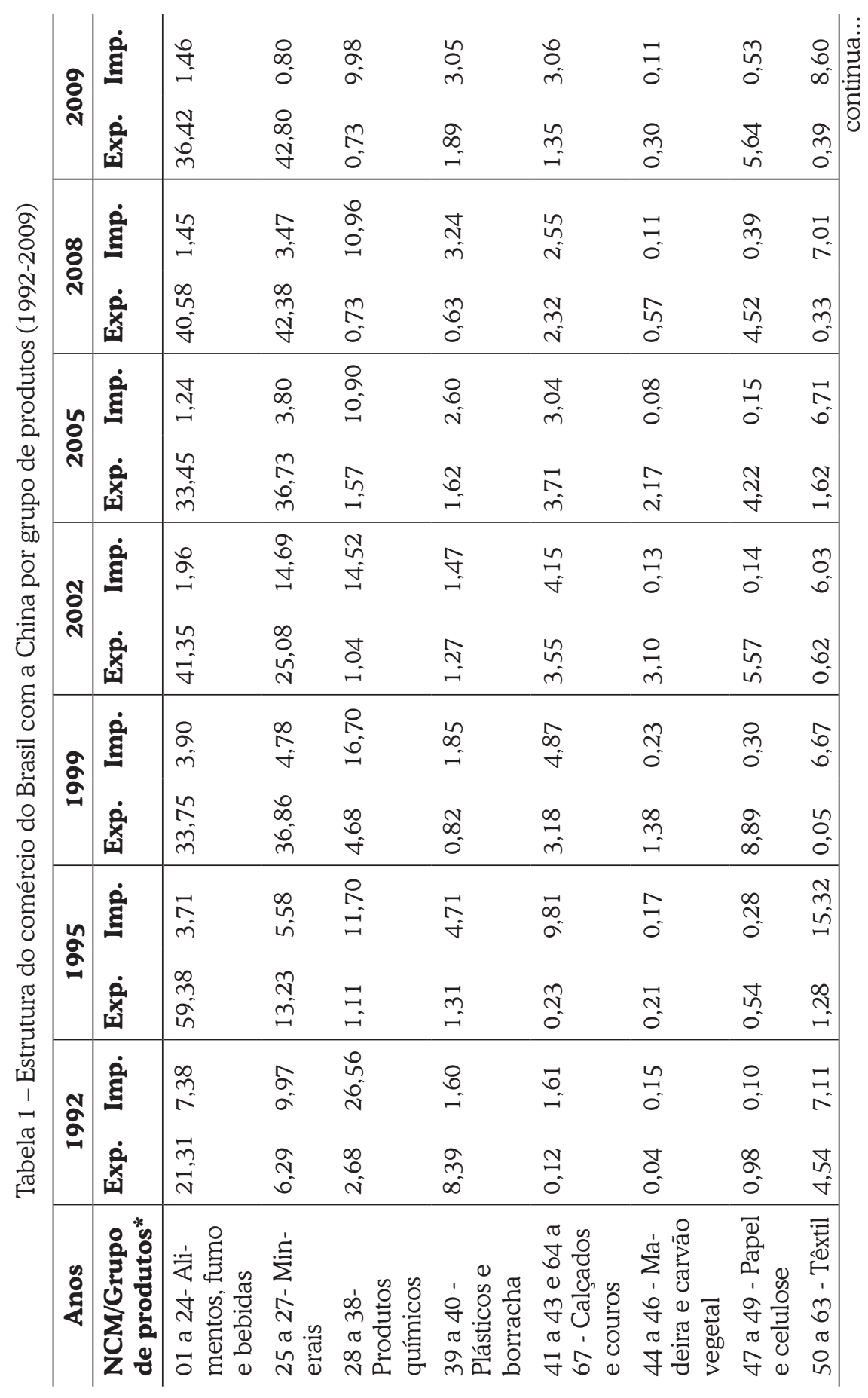




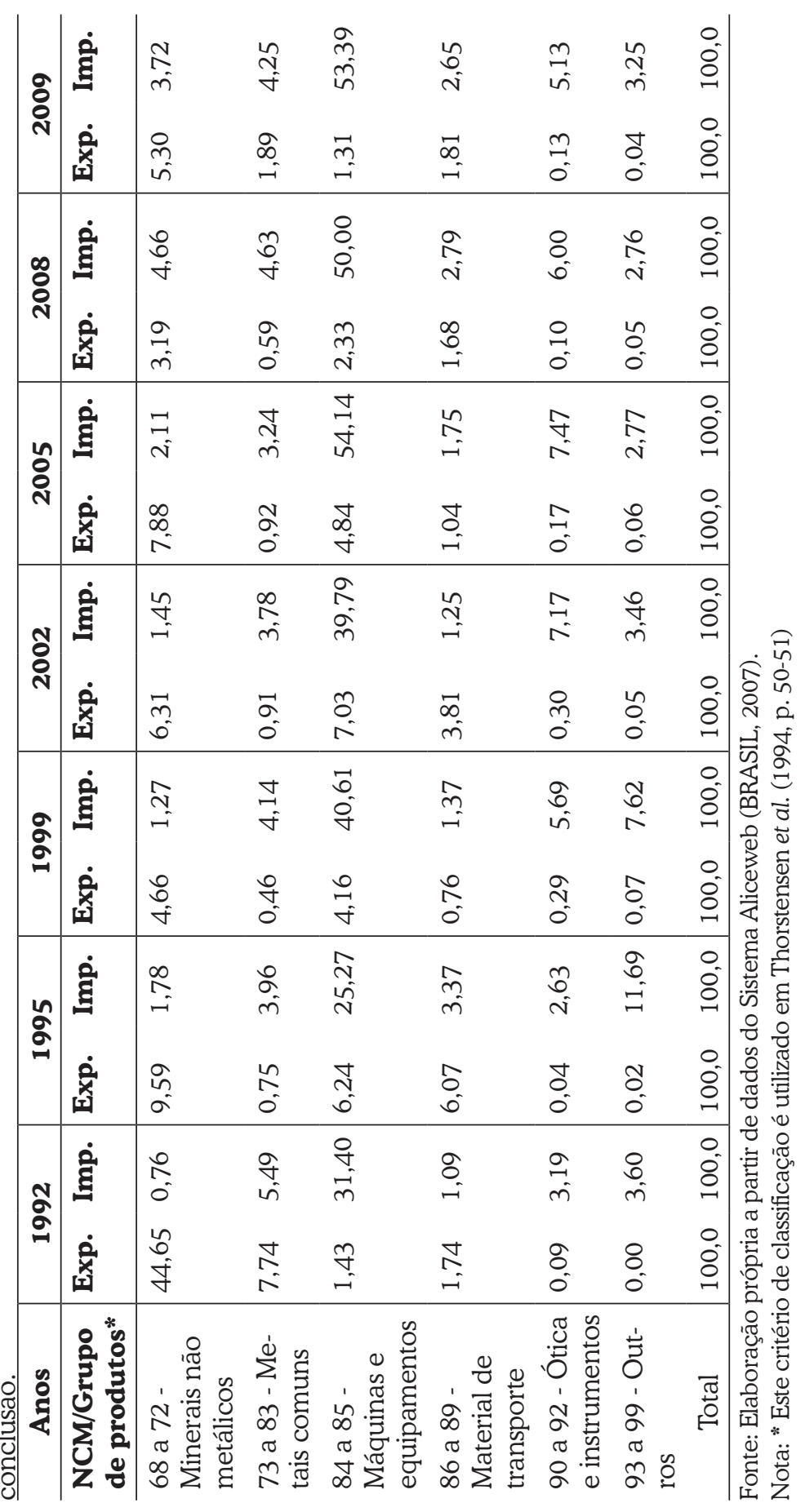


Observa-se na Tabela 1 que o grupo de produtos alimentos e bebidas, que sabidamente tem forte conteúdo de recursos naturais, é o que historicamente apresenta a maior representatividade dentro das exportações do Brasil para a China e tem como destaque a soja. Embora no período analisado não se mantenha um padrão definido, a partir do ano de 1995 houve uma participação significativa desse grupo nas exportações para esse país. Com base nisso, em 1992, o grupo representava $21,31 \%$ do total exportado para China, elevando-se significativamente essa participação, em 1995, para 59,38\% e depois caindo para o nível de representatividade de 33,75\% em 1999. Porém, após o ano de 1999, houve crescimento contínuo do grupo, chegando a representar, em 2008, 40,58\% das exportações brasileiras. No entanto, no ano de 2009, o grupo sofreu o impacto negativo da crise financeira internacional, que se refletiu no comércio internacional, apresentando redução para $36,42 \%$. Certamente a redução da demanda chinesa por bens primários foi determinante para esse desempenho do grupo.

Outro grupo de produtos primários que tem importante destaque na pauta das exportações brasileiras para a China é o grupo de minerais (minérios, combustíveis, etc.). Esse grupo também tem forte conteúdo de recursos naturais e com baixo valor agregado. Observa-se, na Tabela 1, que esse grupo passou a ser o segundo maior em termos de representatividade nas exportações brasileiras para a China, tendo participação anterior de apenas 6,29\% em 1992, se intensificado a partir de 1999, quando atingiu $36,86 \%$, e chegando a representar $42,8 \%$ do valor total exportado para esse país em 2009. Já o grupo de minerais não metálicos, por sua vez, apresentou uma redução de participação relativa no período analisado, passando de 44,65\%, em 1992, para atingir, no final do período em 2009, a representatividade de apenas 5,30\%.

Com relação aos grupos de produtos manufaturados, observa-se, na Tabela 1 , que tiveram uma diminuição significativa de participação relativa nas exportações. Com efeito, no ano de 1989, as exportações de manufaturados que representavam $72,4 \%$ do total exportado para a China passaram a representar apenas 20,7 \% do total em 2009. Fica claro, portanto, a primarização das exportações brasileiras para a China no período recente. A participação dos dois grupos de primários, alimentos e bebidas e minerais, que era de $27,6 \%$, em 1992, passou a representar quase $80 \%$ do total exportado pelo Brasil para a China em 2009.

Analisando agora o comércio com a China pelo lado das importações, na Tabela 1 é apresentada a estrutura das importações brasileiras para esse país segundo os diversos grupos de produtos considerados. Com relação à participação relativa dos grupos de produtos importados pelo Brasil, cabem os seguintes comentários: diferente das exportações, os dados mostram uma redução significativa na participação relativa das importações dos grupos de produtos primários de alimentos e bebidas e de minerais. Esses dois grupos representavam, respectivamen- 
te, 7,38\% e 9,97\% do total importado pelo Brasil da China em 1992, reduzindo a sua participação relativa para apenas 1,46\% e 0,80\% em 2009, respectivamente. Ou seja, a participação desses dois grupos de produtos primários caiu de 17,35\%, em 1992, para o valor representativo mínimo de 2,26\% em 2009. Por outro lado, os produtos manufaturados tiveram crescimento significativo de participação relativa após a abertura comercial. As importações brasileiras de manufaturados durante o período concentraram-se nos grupos de produtos químicos, têxtil, máquinas e equipamentos e ótica e instrumentos, produtos que representaram conjuntamente $77,1 \%$ do total importado no ano de 2009.

Em resumo, diferente das exportações que tem na soja seu principal representante na pauta de exportações de produtos primários para a China, observa-se nas importações uma redução significativa na participação relativa dos grupos de produtos primários e um correspondente incremento na participação relativa dos manufaturados, principalmente daqueles mais intensivos em capital, como é o caso de máquinas e equipamentos, que, em 2009, representavam mais de $50 \%$ do total importado pelo Brasil da China.

Um indicador utilizado neste trabalho a fim de caracterizar melhor o comércio exterior do Brasil com a China é o índice de comércio intraindústria (CII). Trata-se de um índice que permite saber se o comércio realizado é de bens classificados dentro de um mesmo setor (comércio intraindústria), ou de bens classificados em setores diferentes (comércio interindústria). $\mathrm{O}$ índice de CII mais comumente utilizado na literatura é o desenvolvido por Grubel e Lloyd (1975). Esse índice pode ser calculado em nível de produto ou indústria e também em nível agregado para toda a economia. O indicador agregado do CII cunhado por Grubel e Lloyd (1975), utilizado neste trabalho, é calculado com base na equação 1.

$$
C I I=1-\frac{\sum_{i}\left|X_{i}-M_{i}\right|}{\sum_{i}\left(X_{i}+M_{i}\right)}
$$

Na equação 1, $X_{i}$ e $M_{i}$ representam o valor das exportações e das importações do produto $i$, respectivamente. $O$ valor numérico calculado desse índice encontra-se no intervalo entre zero e a unidade. Quando o índice de CII calculado for igual a zero, há ocorrência exclusiva ou de exportações, ou de importações do produto $i$, o que representa comércio interindústria pleno. Por outro lado, quando o índice de CII calculado iguala-se à unidade, quer dizer que o valor das exportações é igual ao valor das importações, então nesse caso todo o comércio é caracterizado como intraindústria.

No Gráfico 1 é apresentado o comportamento dos índices de CII calculados para o comércio Brasil-China, a nível agregado, com dados referentes ao período 
1989-2009. As observações utilizadas para o cálculo do índice de CII desse gráfico foram de acordo com os capítulos da Nomenclatura Comum do Mercosul (NCM). Tendo em vista que o índice de CII é sensível ao nível de agregação das observações utilizadas no cálculo, pode-se esperar que exista uma superestimação do índice de CII calculado conforme os capítulos da NCM. ${ }^{6}$

\section{Gráfico 1- Índice de CII Brasil-China (1989-2009)}

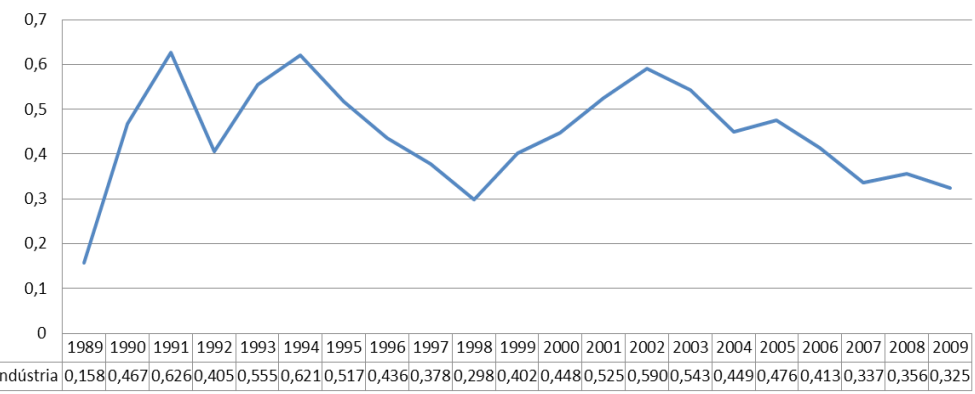

Fonte: Elaboração própria a partir do fluxo de comércio Brasil-China do Sistema Aliceweb (BRASIL, 2007).

Analisando-se o comportamento dos resultados obtidos, observa-se que o comércio Brasil-China é essencialmente do tipo interindústria, pois em 14, dos 21 anos considerados, o CII situa-se em nível abaixo de $0,5 .{ }^{7}$ Conforme pode ser visto no Gráfico 1, o padrão de comércio Brasil-China que inicialmente predomina no período é o CII com índice de apenas 0,158, em 1989, e 0,467 em 1990. Somente nos anos de 1991, 1993 a 1995 e 2001 a 2003, os índices de CII se apresentam mais elevados, porém mesmo assim pouco acima de 0,5.

Os índices de CII encontrados para o comércio Brasil-China se situam abaixo dos níveis encontrados para o comércio entre o Brasil e o resto do mundo e para parceiros comerciais tradicionais, como a Argentina e os demais países do Mercosul. ${ }^{8}$ No caso do comércio Brasil-China, o predomínio do comércio parece ser interindústria, um resultado esperado por se tratar de um intercâmbio que cresceu muito recentemente e está baseado em exportações brasileiras de alimentos e bebidas e de minerais e em importações de manufaturados, tais como máquinas e equipamentos e produtos químicos e têxteis, como visto anteriormente.

6 Quanto mais agregadas (desagregadas) forem as observações utilizadas no cálculo do índice de CII, maior (menor) será o índice de CII obtido.

7 O limite crítico geralmente utilizado na literatura para classificar os produtos entre bens de comércio interindústria e bens de CII é o índice de Grubel e Lloyd, da ordem de 0,5. Para saber mais, ver, por exemplo, Hidalgo (1993).

8 Vasconcelos (2000), por exemplo, encontrou para todos os anos do período 1995-1998 índices de CII no comércio Brasil-Argentina acima de 0,5 para os produtos industrializados. 
Os dados apresentados na Tabela 1 e a intensidade do CII apresentada no Gráfico 1 parecem mostrar uma tendência de especialização do comércio exterior brasileiro com a China, principalmente durante o período recente. A economia brasileira é reconhecidamente bem dotada de recursos naturais (terra e minerais abundantes) e menos dotada de trabalho e capital, em relação à China. ${ }^{9}$

Nas seções a seguir realizar-se-á uma análise mais aprofundada sobre o comércio exterior Brasil-China, em particular a comercialização da soja, a fim de se conhecer melhor quais são os determinantes do comércio desse produto entre os dois países. Isso será feito sob a ótica de um modelo econométrico de curto prazo, cujas variáveis abordadas levam ao desequilíbrio momentâneo entre preço e renda, mas cujas discrepâncias acabam sendo corrigidas nos períodos posteriores.

\section{Método Econométrico Utilizado}

Com base em um modelo econométrico, procurou-se determinar quais são as principais variáveis influenciadoras do comércio de soja entre o Brasil e a China durante o período de 2001-2012. Utilizando-se a teoria econômica, procurou-se identificar os possíveis fatores determinantes nas relações de comércio a fim de se obter um modelo econométrico plausível de ser estimado. ${ }^{10}$ Não obstante a aceitação do modelo empregado, a utilização de séries históricas impõe ao pesquisador cautela, visto o prejuízo de incorrer no fenômeno da regressão espúria. Esse problema ocorre quando, ao se trabalhar com séries temporais, constata-se uma relação estatística significativa entre as variáveis dependente e independente, ainda que elas não possuam a priori correlação alguma. Devido a essa peculiaridade das séries históricas, faz-se necessário o estudo da sua estacionariedade. Sendo as variáveis estacionárias no tempo, ou seja, elas mantendo a média e a variância constantes ao longo do período (no sentido lato), pode-se manipular tais séries

9 A problemática das relações comerciais entre o Brasil e a China vem despertando o interesse por parte dos pesquisadores. Assim, por exemplo, Cunha et al. (2011) estudam a ascensão da China e seus efeitos sobre a economia brasileira, Devlin, Estevadeordal e Rodrigues (2006) analisam as oportunidades e os desafios que a ascensão chinesa representa para América Latina, Módolo e Hiratuka (2012) discutem a concorrência chinesa em terceiros mercados, Feistel e Hidalgo (2012) discutem a questão das vantagens comparativas no comércio bilateral Brasil-China e Silva (2011) analisa os riscos da concorrência chinesa para as exportações brasileiras em terceiros mercados.

10 A estimação de funções de oferta e demanda de exportações é um assunto muito estudado na literatura. Alguns dos principais trabalhos realizados para o Brasil com ênfase em produtos manufaturados são: Pinto (1980), Cardoso e Dornbusch (1980), Braga e Markwald (1983), Zini Jr. (1988), Rios (1987) e Barros e Amazonas (1996). Por outro lado, Barros, Bacchi e Burnquist (2002), Carvalho e De Negri (2002) estimam equações de comércio para produtos agropecuários do Brasil. Para finalizar, Mortatti, Miranda e Bacchi (2011), utilizando uma metodologia semelhante à adotada neste trabalho, analisam os determinantes do comércio Brasil-China para três categorias agregadas de produtos: commodities agrícolas, minerais e produtos industriais, no período 1995-2008. 
como qualquer outra variável de corte temporal, sendo assim passíveis de estabelecimento de relações de longo prazo.

\subsection{Definição das Variáveis}

Segundo Cavalcanti e Ribeiro (1998), a especificação de um modelo de exportação está fundamentada em três premissas teóricas básicas. ${ }^{11} \mathrm{~A}$ primeira é a hipótese do país pequeno. Essa hipótese parte do pressuposto que as vendas externas da nação investigada são uma parcela muito pequena do comércio mundial, sendo incapazes de afetar os preços da mercadoria em questão. A demanda por exportações dessa nação teria uma elasticidade-preço perfeitamente elástica, significando que se o preço do produto oriundo daquele país for maior que sua cotação internacional, não haverá exportação alguma. Por outro lado, "[...] uma leve redução no preço faz com que a quantidade demandada tenda ao infinito" (BESANKO; BRAEUTIGAM, 2004, p. 32). Destarte, haverá somente a possibilidade da estimação de equações de oferta. Nesse caso, as potenciais variáveis explicativas são diversas, dada a "[...] multiplicidade de fatores que podem afetar a capacidade e/ou disposição dos produtores de determinado país em produzir e exportar seus produtos" (CAVALCANTI; RIBEIRO, 1998, p. 18). Entre essas possíveis condicionantes, encontra-se o PIB potencial (proxy da capacidade produtiva do setor exportador), a rentabilidade (mensurada por algum indicador que englobe as receitas e despesas relacionadas às vendas externas), o ciclo de atividade interna e a taxa de câmbio real.

Uma segunda possibilidade para investigar as exportações sugere que a detenção de fração considerável de mercado, ou a produção de mercadorias diferenciadas, considera uma elasticidade-preço finita das exportações. Além disso, a existência de capacidade ociosa na indústria, ou a existência de tecnologia de produção caracterizada pelos retornos constantes de escala, permite supor uma função de oferta perfeitamente elástica, restringindo a possibilidade de estimações de equações de demanda (CAVALCANTI; RIBEIRO, 1998, p. 17).

Teoricamente a lista dos possíveis determinantes da demanda de exportação não é longa, abrangendo basicamente uma variável representando o nível de renda real externa, que esteja relacionada ao consumo de produtos comercializados internacionalmente, e algumas variáveis de preços relativos que denotem a diferença da importância relativa entre produtos domésticos e os substitutos estrangeiros (CAVALCANTI; RIBEIRO, 1998).

11 Mais detalhes sobre os fundamentos teóricos dos determinantes da demanda de exportação e oferta de exportação podem ser encontrados nos trabalhos clássicos de Leamer e Stern (1970) e Goldstein e Khan $(1985,1978)$. 
A terceira interpretação acerca da especificação de modelos de exportação considera como determinantes desta tanto os condicionantes da oferta, quanto os da demanda, partindo-se da premissa que as elasticidades-preços de ambas são finitas. Nesse caso, o preço e a quantidade são determinados simultaneamente pela interação das funções de oferta e demanda (GOLDSTEIN; KHAN, 1978; BARROS; BACCHI; BURNQUIST, 2002).

Neste trabalho pressupõe-se que, sendo o Brasil o segundo maior exportador mundial de soja, a oferta do país impacta no preço internacional da commodity, e, consequentemente, na demanda chinesa, redundando, portanto, em uma elasticidade-preço da demanda finita. Concomitantemente, dado que aproximadamente metade da produção brasileira de soja destina-se ao mercado interno, ${ }^{12}$ fatores que influenciam o consumo no país, a priori, causarão efeitos sobre a fração reservada às exportações, independente do país de destino. Diante disso, presume-se uma elasticidade-preço da oferta igualmente finita.

Assim, com base na análise supracitada empregar-se-á um modelo uniequacional composto por variáveis tanto do lado da oferta quanto do lado da demanda. A hipótese subjacente à pesquisa é a de que o volume total exportado da oleaginosa (exp) está determinado pelo seu nível de preço (pexp), pela renda chinesa (rend) e pela taxa de câmbio real ( $t x$ ), como indicado na equação 2.

$$
\exp =f(p \exp , r e n d, t x)
$$

\subsection{Especificação do Modelo}

Definidas as variáveis explicativas da exportação de soja a serem utilizadas, partiu-se para a especificação funcional do modelo econométrico, o qual se baseou primeiramente em uma análise gráfica da variável dependente contra as independentes. Essa observação levou à utilização de um modelo semelhante ao de Carvalho e De Negri (2000), que foi avaliado, qualitativamente, pelo teste Reset de forma funcional. Esses autores levam em consideração na especificação do modelo as seguintes variáveis: a quantidade exportada, a taxa de câmbio nominal, o preço do produto exportado, o preço doméstico do produto, a taxa média de subsídio (variável considerada de difícil mensuração), a renda interna e a renda externa. Diferentemente de Carvalho e De Negri (2000), este trabalho não levará em conta os subsídios, a renda interna e o preço doméstico do produto. Por outro lado, a taxa de câmbio será considerada em termos reais. Assim, a equação que se pretende estimar está indicada na equação 3.

12 Proposição embasada em dados disponíveis no site do Ministério da Agricultura. 


$$
\exp =\alpha \cdot p \exp ^{\beta} \cdot r e n d^{\lambda} \cdot t x^{\delta} \cdot e^{\varepsilon_{i}}
$$

Expressando a equação 3 em termos de logaritmo, tem-se a equação 4:

$$
\ln \exp =\varphi+\beta \ln p \exp +\gamma \ln r e n d+\delta \ln t x+\varepsilon_{i}
$$

Em que:

exp representa o volume total exportado de soja (outros grãos de soja, mesmo triturados) para a China em toneladas;

pexp representa o preço por tonelada exportada de "outros grãos de soja, mesmo triturados" para a China em dólares americanos;

rend representa a renda chinesa disponível para importação de bens brasileiros. Dada a não disponibilidade de dados mensais da renda chinesa, utilizou-se como proxy para essa variável o valor total das importações agrícolas chinesas de produtos oriundas de todo o mundo, expressas em dólares americanos; ${ }^{13}$

tx representa o índice da taxa de câmbio real;

$\varepsilon_{i}$ representa o erro estocástico, admitindo ter distribuição normal com média zero e variância constante e reunindo todas as demais variáveis que podem influenciar as exportações brasileiras de soja para a China e que não estão incluídas no modelo, seja por pressupostos teóricos, ou impossibilidade de mensuração.

$\varphi=\ln \alpha$.

Ressalta-se que, além da combinação dos dados propiciarem a interpretação de um modelo tal como o expresso pela equação 3, trabalhos empíricos sobre estimação de equações de exportação, como os de Barros, Bacchi e Burnquist (2002), Bittencourt e Sampaio (1999) e Figueiredo e Ferreira Junior (2004), corroboram o uso da forma funcional.

\subsection{Procedimentos Metodológicos}

Para avaliar a existência ou não de relações de longo prazo entre as variáveis selecionadas, e assim inquirir sobre os determinantes da exportação de soja brasileira para a China, seguiram-se os seguintes procedimentos. Primeiro, constatou-se a adequação da forma funcional por meio da análise gráfica e do teste Reset. Em seguida, investigou-se o caráter estacionário das séries através de quatro métodos, quais sejam: método gráfico, análise da função de autocorrelação (gráfico, a es-

13 As importações chinesas são estimuladas pelo crescimento da renda e o consumo doméstico desse país. Na China há uma crescente demanda de proteínas, e, por causa disso, a elevada importação de soja é importante para a alimentação animal. 
tatística $Q$ de Box-Pierce e a estatística de Ljung e Box), teste de Dickey-Fuller ou Dickey-Fuller aumentado e o método de Phillips-Perron. Foram realizados todos os procedimentos para a variável em nível, primeiramente, e, caso não fosse estacionária, a variável foi diferenciada, realizando-se novamente os exames citados. A mesma rotina foi empregada para o erro estocástico $\left(\varepsilon_{i}\right)$.

A existência de relações de longo prazo entre as variáveis é avaliada pelo método de cointegração. Essa análise é realizada por meio dos testes de Engle-Granger, Durbin-Watson ou Johansen. O teste de cointegração de séries temporais utilizado neste trabalho foi o de Johansen. A escolha desse método se justifica, dado que "[...] a abordagem de máxima verossimilhança exposta numa série de artigos de Johansen parece ter atraído a atenção dos investigadores empíricos" (JOHNSTON; DINARDO 2000), ao mesmo tempo em que suplementou os testes de Engle-Granger e Durbin-Watson (GUJARATI, 2006; GREENE, 2008), permitindo a estimação da presença de múltiplos vetores de cointegração em apenas um passo e possibilitando testar diferentes versões restritas dos vetores de cointegração (ENDERS, 2010). Verificada a mesma ordem de integração para as variáveis, e sendo o resíduo estacionário em nível, utilizou-se o método de cointegração de Johansen para a estimação das equações de curto e de longo prazo. Por fim, além da dinâmica de longo prazo, é necessário também estimar como se comportam as exportações quando da ocorrência de choques de curto prazo. Para isso, foi utilizado o mecanismo de correção de erros (MEC), método útil para corrigir possíveis desequilíbrios que ocorram no curto prazo.

O MEC foi desenvolvido e popularizado por Engel e Granger e serve para harmonizar o comportamento no curto prazo de uma variável econômica com seu comportamento de longo prazo (GUJARATI, 2006). Como o mecanismo de correção de erros busca exatamente verificar se há o ajuste necessário para que o equilíbrio seja restaurado, a equação 4 é então modificada para levar em consideração alterações de curto prazo, como definido na equação 5:

$$
\Delta \ln \exp =\varphi+\beta \Delta \ln \exp +\gamma \Delta \ln r e n d+\delta \Delta \ln t x+\xi_{u_{t-1}}+\varepsilon_{i}
$$

\subsection{Dados Utilizados}

Os dados utilizados sobre quantidade exportada de soja para a China e preço das exportações de soja foram coletados do Sistema de Análise de Informações de Comércio Exterior do Aliceweb, da Secretaria de Comércio Exterior (Secex), do Ministério do Desenvolvimento, Indústria e Comércio Exterior (MDIC). As informações sobre importações chinesas, proxy para a variável renda da China, foram obtidas do International Merchandise Trade Statistics (IMTS), das Nações Unidas, Divisão de Estatísticas. Por outro lado, as informações referentes ao índice da taxa 
de câmbio real foram construídas com base em dados do Banco Central do Brasil. A periodicidade das variáveis utilizadas é mensal, tendo início em março de 2001 e término em fevereiro de 2012. Destaca-se que nos meses de dezembro de 2001, janeiro e março de 2002, janeiro de 2003, fevereiro de 2005, janeiro de 2007, janeiro de 2008, dezembro de 2009, janeiro e dezembro de 2010 e janeiro de 2011 não houve exportações de soja para a China, e, nesses casos, utilizou-se como proxy a média da quantidade exportada e dos valores auferidos das vendas nos períodos imediatamente anterior e posterior.

\section{Resultados Obtidos}

Antes da apresentação dos resultados obtidos, deve-se ressaltar quatro pontos. Primeiro, tanto os testes realizados, quanto os gráficos apresentados, foram gerados pelo programa econométrico Microfit 4.0. Segundo, as variáveis exportações de soja (exp), preço por tonelada de soja exportada (pexp), renda chinesa disponível (rend), taxa de câmbio real ( $t x$ ) e erro estocástico serão representadas pelas variáveis $x 1, x 2, x 3, x 4 \mathrm{e} \varepsilon$, respectivamente. Terceiro, o nível de significância padrão utilizado nos testes é de $5 \%$, salvo quando houver referência em contrário. Quarto, o Microfit utiliza os critérios de Akaike e Schwarz de modo inverso, ou seja, quanto maior forem essas estatísticas, melhor especificado estará o modelo. Por último, os dados da segunda e da terceira variável, preço das exportações e renda, foram deflacionados pelo índice de preços ao consumidor dos Estados Unidos (CPI), fornecido pelo Bureau of Labor Statistics do Departamento do Trabalho do país.

\subsection{Modelo Empregado}

A análise dos gráficos da quantidade exportada de soja contra cada variável dependente, preço da soja, renda chinesa e taxa de câmbio real, mostra uma relação não linear entre aquela e estas, o que é respaldado pelo teste da forma funcional (Reset), que apontou um $F$ calculado de 4,7207, cujo valor $p^{14}$ é de 3,2\% para 01 grau de liberdade no numerador e 127 no denominador, significando que, a um nível de significância de $1 \%$, não se pode rejeitar a equação 6 . A estimação obtida para o modelo é indicada na equação 6:

$$
\begin{aligned}
& \ln x 1=-27,36-2,3596 \ln x 2+2,7317 \ln x 3+0,9168 \ln x 4+\varepsilon_{t} \\
& \begin{array}{lllll}
e p & (16,2396) & (0,90907) & (0,70950) & (1,0579)
\end{array} \\
& \begin{array}{lllll}
t & 0,0940 & 0,0110 & 0,0007 & 0,3880
\end{array} \\
& F=4,7207(0,032)
\end{aligned}
$$

14 O valor $p$, ou nível de significância exato, é o menor nível de significância a que se pode rejeitar a hipótese nula (GUJARATI, 2006, p. 111). 
Em que: $\ln x 1, \ln x 2, \ln \times 3$ e $\ln x 4$ significam, respectivamente, logaritmo natural da quantidade exportada, logaritmo natural do preço, logaritmo natural da renda e logaritmo natural da taxa de câmbio real; $\varepsilon$ é o erro estocástico; ep significa erro padrão; e $t$ corresponde à estatística $t$ de student.

A representação gráfica dos valores estimados e valores observados para o logaritmo natural das exportações aparecem no Gráfico 2, e se não mostram perfeita consonância, pelo menos possuem os mesmos movimentos ao longo do período analisado. ${ }^{15}$

Gráfico 2 - Valores estimados e valores reais para o logaritmo natural das exportações

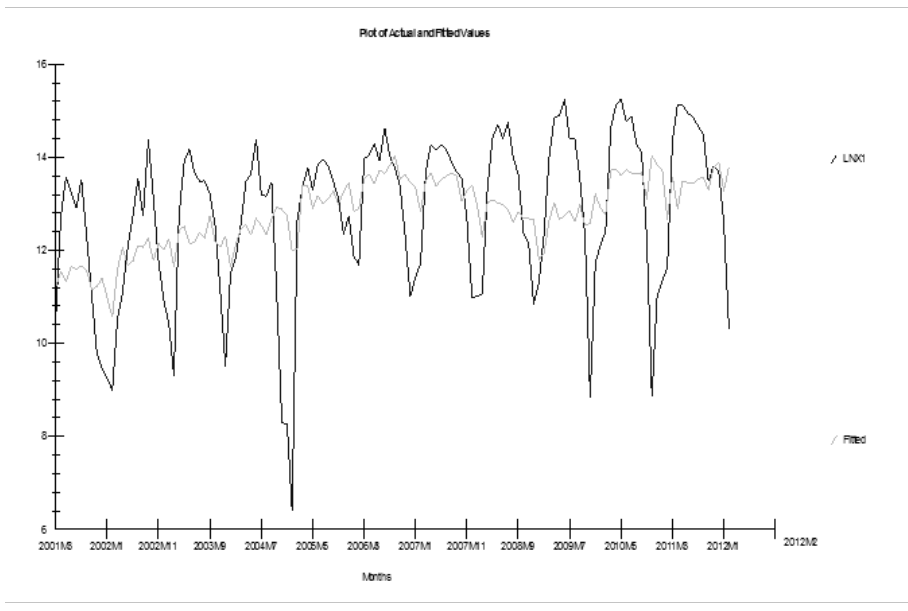

Fonte: Elaboração própria.

Nota: $\ln x 1$ significa logaritmo natural da quantidade exportada.

\subsection{Estacionariedade das Séries}

Como já foi dito, para não incorrer no fenômeno da regressão espúria, faz-se necessário uma análise da estacionariedade das variáveis, a qual se realizará através dos seguintes testes: análise gráfica, análise da função de autocorrelação (FAC), teste de Box-Pierce (BP), teste de Ljung-Box (LB), teste de Dickey-Fuller (DF) e teste de Phillips-Perron (PP). Caso a proxy seja determinada como não estacionária, será diferenciada, e uma nova rodada de testes será aplicada.

A Tabela 2 mostra os resultados obtidos através dos testes de estacionariedade. Para a variável quantidade exportada $(\ln x 1)$, preço de exportação $(\ln x 2)$,

15 O Gráfico 2 mostra uma redução brusca da quantidade exportado de soja (lnx1) para a China em 2004. Queda essa motivada em parte pela suspensão das importações chinesas de soja brasileira nesse ano, tendo em vista que o governo chinês considerou que o cereal estava contaminado. 
renda chinesa (lnx3), taxa de câmbio real $(\ln \times 4)$ e o resíduo, a interpretação gráfica contra o tempo sugere que, entre março de 2001 e fevereiro de 2012, a quantidade exportada de soja para a China não permaneceu estável, pois manteve uma variação inconstante no período. Com isso, pressupõe-se a não estacionariedade das séries para todas as variáveis.

Tabela 2 - Análise de estacionariedade das séries*

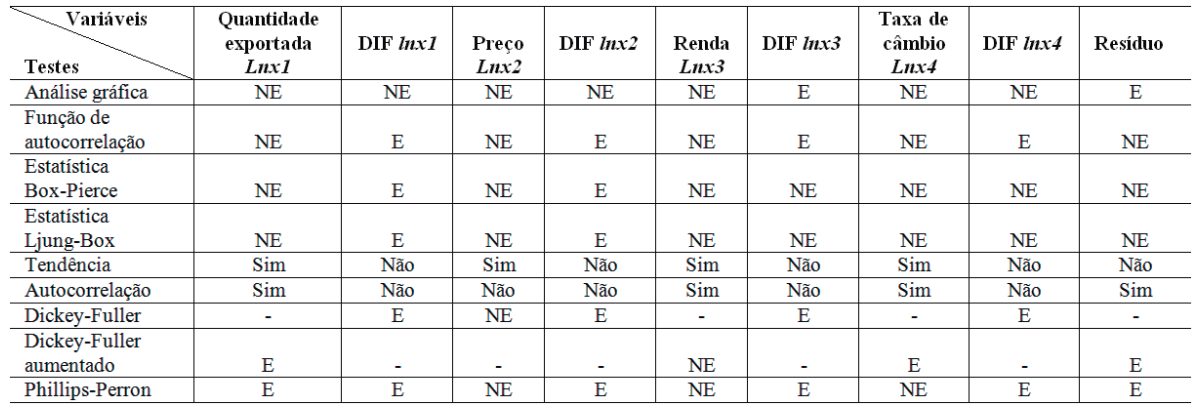

Fonte: Elaboração própria.

Nota:* $N E$ significa que a série é não estacionária e $E$ significa que a série é estacionária.

\subsubsection{A Variável Quantidade Exportada: Inx 1}

Os resultados da Tabela 2 destacam na análise gráfica uma variabilidade distinta ao longo dos anos, concluindo-se pela não estacionariedade da série. Além disso, tanto a FAC, que mostra uma queda gradual nas quatro primeiras defasagens, quanto as estatísticas Box-Pierce e Ljung-Box, que se mostram significativas para todas as 44 defasagens, corroboram a condição de não estacionariedade da série.

Verificada a significância da tendência (valor $p$ inferior a 1\%), e a ocorrência de autocorrelação positiva (valor calculado de 1,5438, inferior ao valor crítico de 1,715), aplicou-se o teste Dickey-Fuller aumentado (ADF) com tendência, que apresentou, de acordo com o critério Schwarz (SBC) em três defasagens, uma estatística de 7,1858, superior em módulo ao valor crítico de 3,4478, decidindo-se, então, pela rejeição da hipótese da não estacionariedade. Por sua vez, o teste PP permitiu chegar à mesma conclusão, visto que a estatística t foi de 4,4265 e, portanto, superior a 3,4478 (ver Tabela 2).

Baseado nos quatro primeiros testes partiu-se para a diferenciação da variável $\ln x 1$, a qual se mostrou estacionária em todas as avaliações, a exceção da análise gráfica, que apresentou uma variação menor do que as exportações em nível, mas mesmo assim alterou-se ao longo do tempo.

Na segunda defasagem, a FAC caiu abruptamente e as estatísticas BP e LB mostraram-se não significativas ( $p>5 \%$ ) até a quarta defasagem. A diferenciação 
de $\ln x 1$ não possui tendência ( $p=56,8 \%$ ), nem autocorrelação (valor calculado de 1,995 e valor crítico de 1,694), implicando um teste DF sem tendência. Esse resultou tem uma estatística de 9,7741, superior ao valor crítico de 2,8859 . O teste PP apresentou valor calculado de 10,2021, também mais elevado que 2,8859. Destarte, a quantidade exportada para a China é estacionária em primeira diferença.

\subsubsection{A Variável Preço de Exportação: $\ln x 2$}

Ao longo do período analisado, a variável preço de exportação mostra inicialmente uma tendência ascendente (de março de 2001 a dezembro de 2004), logo caindo e estabilizando-se (de janeiro de 2005 a junho de 2007), e voltando a crescer (de julho de 2007 a fevereiro de 2012). Dessa maneira, a série não possui estabilidade no período avaliado. Também, na Tabela 2, é mostrada a não estacionariedade para essa variável, em que a FAC possui um decréscimo suave para as 44 defasagens, indo na mesma direção das estatísticas BP e LB, significativas para todas as defasagens ( $p$ inferior a 1\%), caracterizando a não estacionariedade. Constatada a tendência ( $p<1 \%$ ), e a inexistência da autocorrelação (valor calculado de 1,7861 maior que o valor crítico de 1,76), aplicou-se o teste DF com tendência, cujo valor calculado foi de 2,6782, inferior ao valor crítico de 3,4478. A estatística PP foi calculada em 1,5361, mais uma vez menor que o valor crítico. Portanto, a sucessão é não estacionária em nível. Em seguida, aplicou-se a diferenciação. A análise gráfica das diferenças da variável lnx2 mostrou uma grande variabilidade, enquanto a FAC (queda acentuada na segunda defasagem), e as estatísticas BP e LB (não significativas para 44 defasagens), sustentam a hipótese da estacionariedade. A nova série não possui tendência ( $p=89,10 \%$ ), muito menos autocorrelação ( $\mathrm{DW}=1,9957)$, sendo aplicado, então, o teste $\mathrm{DF}$, que apresentou a estatística de 10,4005, maior que o valor crítico de 2,8859. O teste PP mostrou valor $t$ igual a 10,7279, acima de 2,8859. Dessa forma, concluiu-se pela estacionariedade em primeira diferença da variável preço de exportação.

\subsubsection{A Variável Renda: $\ln x 3$}

O gráfico da variável renda plotada no tempo mostra uma elevação contínua da média até outubro de 2008, quando caiu sucessivamente até fevereiro de 2012, e, então, iniciou um movimento de recuperação que se estende até o final do período considerado. Em consonância com a análise gráfica, a FAC mostra um típico caso de não estacionariedade, em que seus valores caem vagarosamente com as defasagens. As estatísticas BP e LB são todas significativas ( $p$ inferior a 1\%) para as 44 defasagens e não estacionárias como mostra a Tabela 2. Ainda, na Tabela 2, a série em questão possui tendência ( $p$ menor que 1\%) e autocorrelação negativa, 
pois o valor calculado de 2,3005 é maior que o valor crítico de 2,285. Desse modo, aplicou-se o teste $\mathrm{ADF}$, que tanto pelo critério de $\mathrm{AIC}$, quanto pelo critério de $\mathrm{SBC}$, apontou para uma estatística teste de 2,6882 (12 defasagens), menor que o valor crítico de 3,4478. O teste PP indicou um valor calculado de 1,6869, novamente inferior a 2,6882. Logo, todos os procedimentos obtiveram o mesmo resultado, qual seja, a não rejeição da hipótese de não estacionariedade, levando, então, à diferenciação da série. A série das diferenças de $\ln x 3$ mostra uma variabilidade mais constante que as demais. O gráfico da FAC também segue na direção da estacionariedade da sucessão, entretanto, as estatísticas BP e LB continuam significativas para todas as 43 defasagens. Essa segunda proxy não possui tendência ( $p 84,3 \%$ ), nem autocorrelação negativa, visto que o valor calculado de 2,2595 é menor que o valor crítico de 2,306 . Utilizando-se o teste DF sem tendência, achou-se a estatística teste de 16,7179, maior que o valor crítico de 2,8859. O teste PP encontrou um valor de 16,8965, ratificando os testes gráficos, a FAC e o DF. A série é estacionária em primeira diferença, como mostra a Tabela 2.

\subsubsection{A Variável Taxa de Câmbio Real: $\ln x 4$}

A variável taxa de câmbio real, quando avaliada no tempo, mostra depreciação até dezembro de 2002, quando inverte o movimento e começa a se apreciar, continuando nessa tendência ao longo do período estudado. Sua FAC é característica de um processo não estacionário, pois diminui pausadamente, além de que as estatísticas BP e LB são significativas nas 44 defasagens. A sucessão possui tendência, sendo que esta é significativa a 1\%, e autocorrelação (valor calculado de 1,2588, menor que o valor crítico de 1,715). O teste ADF com uma defasagem (critério SBC) apresentou uma estatística teste de 3,5882, maior que o valor crítico de 3,4478, ou seja, indicou estacionariedade. Todavia, o teste PP calculou um valor de 0,22992, menor, portanto, que o valor crítico de 3,5882. Fundamentando-se na análise gráfica, na FAC e nos testes BP, LB e PP, como mostrado na Tabela 2, se aceitou a hipótese de não estacionariedade e, consequentemente, se diferenciou a variável $\ln \times 4$. A avaliação gráfica constatou uma variabilidade distinta no período abrangido pelo estudo, portanto, não estacionário. Já a FAC possuiu queda acentuada na segunda defasagem, contudo as estatísticas BP e LB ainda continuaram significativas para 44 defasagens. A diferença de $\ln x 4$ não possuiu tendência ( $p$ $=38,9 \%$ ), nem ao menos autocorrelação ( $\mathrm{DW}=2,0058$ ), então se usou DF sem tendência, o qual resultou em uma estatística teste de 7,5529, maior que o valor crítico de 2,8859. O teste PP mostrou o mesmo resultado, qual seja, a sucessão é estacionária (valor calculado 7,8523). Destarte, a variável lnx4 é estacionária em primeira diferença. 


\subsubsection{O Resíduo}

Por fim, na Tabela 2 é mostrada a análise da estacionariedade do resíduo. Inicialmente, a análise gráfica do resíduo o mostrou relativamente comportado no período, havendo duas discrepâncias mais acentuadas entre os meses de agosto de 2004 e de março de 2005, e entre junho de 2010 e março de 2011. A FAC apresentou uma queda na segunda defasagem, porém sem ser vertiginosa. As estatísticas BP e LB foram todas significativas até a $44^{\text {a }}$ defasagem, indicando a não estacionariedade. A série não apresentou tendência ( $p=96,5 \%$ ), mas foi constatada a autocorrelação (valor calculado de 1,6131, inferior ao valor crítico de 1,694). O teste ADF para uma defasagem (AIC) encontrou a estatística teste de 5,0690, que é superior ao valor crítico de 2,8857. Na mesma direção, o teste PP achou o valor de 4,5462, novamente mais elevado que o valor crítico. Assim, a variável resíduo é considerada estacionária em nível. Dessa forma, com base na análise acima, concluiu-se que as variáveis são estacionárias em primeira diferença e que o resíduo é em nível, assim atendeu-se aos requisitos necessários para se realizar a análise de cointegração.

\subsection{Análise de Cointegração}

Atendidos os pressupostos para a cointegração, verificou-se a ordem do vetor autorregressivo. Com base no critério de Akaike (AIC), a escolha das defasagens ficou em quatro, indicando que as variáveis estudadas possuem influência de até quatro períodos anteriores. Deve-se ressaltar que o critério de Schwarz (SBC) apontou para uma defasagem, mas levando-se em consideração o critério de máximo verossimilhança (LL) para o desempate, que indicou um valor de 278,7893, para o primeiro, e de 231,3180 para o segundo, optou-se pelo AIC.

Empregando o método de cointegração de Johansen com intercepto restrito e sem tendência para um VAR de ordem quatro, foram encontrados os seguintes resultados: primeiro, pelo critério do autovalor máximo, rejeitou-se a hipótese nula da inexistência de vetores de integração. A estatística calculada foi superior ao valor crítico, indicando que há alguma relação de longo prazo entre as variáveis analisadas, como comprovado na Tabela 3. 
Tabela 3 - Teste de cointegração de Johansen (vetores com base no critério do autovalor máximo)

\begin{tabular}{|c|c|c|c|}
\hline Hipótese nula & $\begin{array}{l}\text { Hipótese alter- } \\
\text { nativa }\end{array}$ & Estatística & $\begin{array}{l}\text { Valor crítico a } \\
95 \%\end{array}$ \\
\hline $\mathbf{r}=\mathbf{0}$ & $\mathbf{r}=1$ & 54,2704 & 28,2700 \\
\hline$r<=1$ & $r=2$ & 12,4487 & 22,0400 \\
\hline$r<=2$ & $r=3$ & 11,5054 & 15,8700 \\
\hline$r<=3$ & $r=4$ & 4,6212 & 9,1600 \\
\hline
\end{tabular}

Fonte: Elaboração própria.

Da mesma forma, utilizando o teste traço, este assinalou a rejeição da não ocorrência de relações de longo prazo, pois, novamente, a estatística calculada foi maior que o valor crítico, como mostrado na Tabela 4.

Tabela 4 - Teste de cointegração de Johansen (vetores com base no critério do traço)

\begin{tabular}{|c|c|c|c|}
\hline Hipótese nula & $\begin{array}{l}\text { Hipótese alter- } \\
\text { nativa }\end{array}$ & Estatística & $\begin{array}{l}\text { Valor crítico a } \\
95 \%\end{array}$ \\
\hline $\mathbf{r}=\mathbf{0}$ & $r>=1$ & 82,8457 & 53.4800 \\
\hline $\mathrm{r}<=1$ & $\mathrm{r}>=2$ & 28,5753 & 34.8700 \\
\hline $\mathrm{r}<=2$ & $r>=3$ & 16,1266 & 20.1800 \\
\hline $\mathrm{r}<=3$ & $r=4$ & 4,6212 & 9.1600 \\
\hline
\end{tabular}

Fonte: Elaboração própria.

Quanto ao número de vetores cointegrantes, o AIC resultou em quatro, enquanto que o SBC indicou apenas um. Considerando o critério LL para o desempate, optou-se pelo resultado obtido pelo AIC, como pode ser visto na Tabela 5.

Tabela 5 - Teste de cointegração de Johansen (vetores com base no AIC e Schwarz)

\begin{tabular}{crrc}
\hline Posto & \multicolumn{1}{l}{ LL } & \multicolumn{1}{l}{ AIC } & SBC \\
\hline $\mathrm{r}=0$ & 319.7345 & 271.7345 & 203.2858 \\
$\mathrm{r}=1$ & 346.8697 & 290.8697 & $\mathbf{2 1 1 . 0 1 2 8}$ \\
$\mathrm{r}=2$ & 353.0940 & 291.0940 & 202.6811 \\
$\mathrm{r}=3$ & 358.8467 & 292.8467 & 198.7297 \\
$\mathbf{r}=\mathbf{4}$ & $\mathbf{3 6 1 . 1 5 7 3}$ & $\mathbf{2 9 3 . 1 5 7 3}$ & 196.1883 \\
\hline
\end{tabular}

Fonte: Elaboração própria. 
Levando-se em conta os resultados dos testes de autovalor máximo e traço, que mostraram existir pelo menos um vetor cointegrante, e para fins de estimação da equação de longo prazo, empregou-se apenas um vetor de cointegração, visto que o objetivo do trabalho é verificar a relação entre a variável dependente e as demais. Tendo como premissa esses resultados, foram geradas as estimativas constantes na Tabela 6, na qual a variável dependente (lnx1) foi normalizada.

Tabela 6 - Resultados da estimação da regressão

\begin{tabular}{cccccc}
\hline & $\boldsymbol{l n} \boldsymbol{x} \mathbf{1}$ & $\boldsymbol{\operatorname { l n } x \boldsymbol { 2 }}$ & $\boldsymbol{\operatorname { l n } x \mathbf { 3 }}$ & $\boldsymbol{\operatorname { l n } x \boldsymbol { 4 }}$ & Constante \\
\hline $\mathrm{Bi}$ & 1,0000 & -0.83291 & 1.7716 & 0.30290 & -15.9680 \\
$\mathrm{Ep}$ & -- & $(0.97187)$ & $(0.88343)$ & $(1.2635)$ & $(20.1810)$ \\
$\mathrm{T}_{\text {calculado }}$ & -- & 0,85702 & $\mathbf{- 2 , 0 0 5 3 7}$ & $-0,23973$ & 0,79124 \\
$\mathrm{~T}_{\text {critico }}$ & -- & 1,98 & 1,98 & 1,98 & 1,98 \\
\hline
\end{tabular}

Fonte: Elaboração própria.

É possível verificar que quando a variável quantidade exportada é normalizada, tanto os preços de exportação quanto a taxa de câmbio real tornam-se não significativos, mas a variável renda permanece como fator decisivo nas mudanças da variável $\ln x 1$. Constata-se que, para cada $1 \%$ de variação na renda chinesa, a demanda pelas nossas exportações de soja eleva-se em 1,7716\%. Dessa forma, espera-se que se a renda chinesa destinada às importações aumentar, então as vendas brasileiras da oleaginosa para esse país crescerão mais que proporcionalmente. ${ }^{16}$ Por outro lado, a elasticidade das exportações de soja em relação à taxa de câmbio real é de 0,3029, ou seja, é inelástica, porém não é estatisticamente significativa, pois o $t$ calculado $(0,23973)$ está abaixo do $t$ crítico $(1,98)$. Assim, pode-se concluir que a taxa de câmbio real não parece afetar significativamente as exportações de soja para a China. ${ }^{17}$

Os resultados encontrados para as elasticidades da demanda chinesa por soja brasileira mostram que ela é elástica em relação à renda e evidenciam a importância de especificar o modelo completo de oferta e demanda de soja para o estudo dos determinantes das exportações do produto. Além da dinâmica de longo prazo, é necessário também se estimar como se comporta a renda quando

16 A importância da renda estrangeira como determinante das exportações agrícolas brasileiras já foi constatada por outros autores, como Mortatti, Miranda e Bacchi (2011), por exemplo, que constataram que a variável proxy para a renda da China tem alto poder explicativo a respeito das exportações brasileiras, principalmente sobre as commodities agrícolas e minerais, e Carvalho e De Negri (2000), que encontraram que as exportações são muito afetadas pelo nível de atividade mundial e pouco afetadas pela taxa de câmbio.

17 Parece ser um resultado coerente com a literatura. Carvalho e De Negri (2000) encontraram, por exemplo, que as exportações agropecuárias do Brasil são pouco afetadas pela taxa de câmbio real. 
da ocorrência de choques no curto prazo. Para isso, empregou-se o modelo de correção de erros (MCE), cujos resultados estão expostos na Tabela 7.

Tabela 7 - Estimativa da equação de correção de erros para $\ln x 1$

\begin{tabular}{ccccc}
\hline Variável & $\begin{array}{c}\text { Coeficiente } \\
\text { estimado }\end{array}$ & $\begin{array}{c}\text { Desvio pa- } \\
\text { drão }\end{array}$ & T $_{\text {Calculado }}$ & Valor $\boldsymbol{p}$ \\
\hline $\operatorname{difln} \times 11^{1}$ & 0.40017 & 0.088137 & 4.5404 & 0.000 \\
$\operatorname{difln} \times 21^{2}$ & 3.16740 & 1.477900 & 2.1432 & 0.034 \\
$\operatorname{difln} \times 12^{3}$ & 0.45622 & 0.093413 & 4.8839 & 0.000 \\
$\operatorname{difln}^{2} 13^{4}$ & 0.37039 & 0.098119 & 3.7749 & 0.000 \\
mce $^{5}$ & -0.66615 & 0.090941 & -7.3250 & 0.000 \\
\hline
\end{tabular}

Fonte: Elaboração própria.

Notas: ${ }^{1}$ dLNX11 $=\operatorname{LNX1}(-1)-\operatorname{LNX} 1(-2) ;{ }^{2}$ dLNX21 $=\operatorname{LNX2}(-1)-\operatorname{LNX} 2(-2) ;{ }^{3}$ dLNX12 $=$ LNX1 $(-$ 2) $\operatorname{LNX1}(-3) ;{ }^{4} \mathrm{dLNX13}=\operatorname{LNX1}(-3)-\operatorname{LNX1}(-4) ;{ }^{5} \mathrm{mce} 1=1.0000 * \operatorname{LNX} 1+0.83291{ }^{*} \operatorname{LNX} 2$ -1.7716 *LNX3 $-0.30290 *$ LNX4+15.9680.

No curto prazo, é possível observar na Tabela 7 que a variável lnx1 é influenciada por si mesma defasada em um, dois e três períodos, e pelo preço defasado em um período. As discrepâncias do valor de equilíbrio das exportações em um dado mês são corrigidas em $66,6 \%$ no mês subsequente, caracterizando um rápido retorno à média. Portanto, os efeitos de choques ocorridos em um período qualquer são retificados ao longo do tempo.

\section{Considerações Finais}

O comércio entre o Brasil e a China intensificou-se nos últimos anos e caracteriza-se por vendas brasileiras concentradas em produtos primários, seja de origem vegetal ou mineral. Dentre os principais produtos comercializados com a China, destaca-se a soja, que vem respondendo por aproximadamente $30 \%$ da totalidade das exportações brasileiras para esse mercado. Tendo em vista a importância da soja no comércio com a China e a preocupação do governo em aumentar as exportações, justifica-se conhecer quais são as variáveis que determinam a quantidade exportada do produto para esse mercado. O conhecimento do valor das elasticidades permite realizar previsões sobre o comportamento futuro das exportações do setor. Para tanto, partindo da hipótese de que o preço do produto, a renda chinesa e a taxa de câmbio real são as principais variáveis que influenciam as exportações, fez-se a modelagem econométrica proposta e a posterior análise dos resultados.

Com base na observação dos testes econométricos realizados, conclui-se que as variáveis utilizadas possuem a mesma ordem de integração e o resíduo é esta- 
cionário em nível, atendendo, assim, aos pressupostos da teoria de cointegração. Constatou-se que, quando a variável quantidade exportada é normalizada, tanto os preços de exportação quanto a taxa de câmbio real tornam-se não significativos, mas a variável renda permanece como fator decisivo nas mudanças de exportações de soja brasileira para a China.

Verificada a existência de vetores cointegrantes, examinou-se a possibilidade da variável exportações de soja ser uma combinação linear das demais, o que mostrou-se ser verdadeiro apenas para a proxy da renda chinesa. Para cada $1 \%$ de alteração na renda chinesa destinada às importações, a demanda por exportações brasileiras de soja em grão aumenta em aproximadamente 1,77\%. Por outro lado, as exportações de soja para a China não parecem ser afetadas significativamente diante de uma mudança na taxa real de câmbio. Portanto, os resultados obtidos parecem sugerir que cenários de estagnação da economia chinesa provavelmente prejudicarão as exportações de soja, ao passo que a desvalorização da moeda terá pouca repercussão nas exportações de soja para a China.

Em compensação, no curto prazo, a renda perde significância e a variável preço torna-se significativa para uma defasagem, significando que os preços do período anterior afetam as exportações do período corrente e que os valores divergentes da média em um dado mês são corrigidos no mês subsequente em $66 \%$.

Os resultados também evidenciam a importância de se conhecer melhor as relações de simultaneidade entre a demanda e a oferta para o estudo dos determinantes das exportações de soja para a China. A suposição de que no comércio de soja entre o Brasil e a China o país está diante de uma demanda infinitamente elástica não parece ter respaldo empírico.

Como todo trabalho empírico, este também tem suas limitações, a mais importante delas está relacionada à qualidade dos dados que foram utilizados. Idealmente deveria ser utilizada a renda chinesa mensal disponível para importação de bens brasileiros. Tendo em vista a não disponibilidade dessas informações para o período considerado, utilizou-se como proxy para essa variável o valor total das importações agrícolas chinesas de produtos oriundas de todo o mundo. Melhorias nos resultados poderiam ser obtidas na medida em que se disponha de melhores dados para essa variável.

\section{Referências}

BARROS, A. R.; AMAZONAS, A. Manufactured exports from Brazil: determinants and consequences. Revista Brasileira de Economia, v. 50, n. 1, p. 73-100, 1996.

BARROS, G. S. C.; BACCHI, M. R. P.; BURNQUIST, H. L. Estimação de equações de oferta de exportação de produtos agropecuários para o Brasil (1992/2000). Rio de Janeiro: Ipea, 2002. (Texto para Discussão, n. 865). 
BESANKO, D.; BRAEUTIGAM, R. R. Microeconomia: uma abordagem completa. Rio de Janeiro: LTC, 2004.

BITTENCOURT, M. V. L.; SAMPAIO, A. V. Estimação da função de exportação de café para o Brasil, 1983-1998. In: CONGRESSO BRASILEIRO DE ECONOMIA E SOCIOLOGIA RURAL DA SOBER, 37., 1999, Foz do Iguaçu. Anais... Foz do Iguaçu: Sober, 1999.

BRAGA, H. C.; MARKWALD, R. A. Funções de oferta e de demanda das exportações de manufaturados no Brasil: estimação de um modelo simultâneo. Revista Pesquisa e Planejamento Econômico, v. 13, n. 3, p. 707-744, 1983.

BRANDÃO, A. S.; LIMA, E. C. R. Impacts of the U. S. subsidy to soybeans on world prices, production and exports. Revista de Economia e Sociologia Rural, v. 44, n. 4, p. 631-676, 2006.

BRASIL. Ministério da Agricultura. Informes de Mercado. 2007. Disponível em: http://www. agricultura.gov.br/arq_editor/file/Interc\%C3\%A2mbio\%2007/China.pdf. Acesso em: 22 abr. 2007.

Ministério do Desenvolvimento, Indústria e Comércio Exterior. Secretaria de Comércio Exterior. Aliceweb: dados das exportações brasileiras por períodos. Disponível em: <http://www.aliceweb.desenvolvimento.gov.br>. Acesso em: 22 abr. 2007.

CARDOSO, E.; DORNBUSCH, R. Uma equação para as exportações brasileiras de produtos manufaturados. Revista Brasileira de Economia, v. 34. n. 3, p. 429-438, 1980.

CARVALHO, A.; DE NEGRI, J. A. Estimação de equações de importação e exportação de produtos agropecuários para o Brasil (1977/1998). Rio de Janeiro: Ipea, jan. 2000. (Texto para Discussão, n. 698).

CARVALHO, M. A.; SILVA, C. R. L.; GHILARDI, A. A. Competitividade da soja e a geração de divisas. Revista de Economia e Agronegócio, v. 3, n. 3, p. 301- 321, 2005.

CAVALCANTI, M. A. F. H.; RIBEIRO, F. J. As exportações brasileiras no período 1977/96: desempenho e determinantes. Rio de Janeiro: Ipea, 1998. (Texto para Discussão, n. 545).

CORONEL, D. A.; MACHADO, J. A.; CARVALHO, F. M. Análise da competitividade das exportações do complexo soja brasileiro de 1995 a 2006: uma abordagem de market-share. Revista de Economia Contemporânea, v. 13, n. 2, p.281-307,2009.

CUNHA, A. M. et al. Breves considerações sobre os impactos potenciais da ascensão da China na economia brasileira. In: SEMINÁRIO SOBRE PESQUISAS EM RELAÇÕES ECONÔMICAS INTERNACIONAIS, 2., 2011, Brasília, DF. Anais... Brasília, DF: FUNAG, 2011. p. 9-47.

DEVLIN, R.; ESTEVADEORDAL, A.; RODRÍGUEZ, A. (Coord.). The Emergence of ChinaOpportunities and Challenges for Latin America and the Caribbean. Washington, D.C.: Banco Interamericano de Desenvolvimento; David Rockefeller Center for Latin American Studies e Harvard University, 2006.

ENDERS, W. Applied econometric time series. 3. ed. USA: John Wiley E Sons, 2010.

FEISTEL, P.; HIDALGO, A. O Intercâmbio Comercial Brasil-China: A Questão das Vantagens Comparativas. Revista Análise Econômica, v. 29, n. 57, p. 175-203, 2012. 
FIGUEIREDO, A. M.; FERREIRA JUNIOR, S. Função de exportação brasileira de soja em grão: análise e considerações sobre seus determinantes no período de 1980 a 2002. In: CONGRESSO BRASILEIRO DE ECONOMIA E SOCIOLOGIA RURAL DA SOBER, 42., 2004, Cuiabá. Anais... Cuiabá: Sober, 2004.

FIGUEIREDO, A. M.; SANTOS, M. L.; LIRIO, V. S. Análise de market-share e fontes de variação das exportações brasileiras de soja. Revista de Economia e Agronegócio, v. 2, n. 3, p. 335- 359, 2004a.

. Diferenciação por origem e substituição nas exportações de soja em grão do Brasil, dos EUA e da Argentina. Revista de Economia e Agronegócio, v. 2, n. 4, p. 431-447, 2004b.

FOOD AND AGRICULTURE ORGANIZATION OF THE UNITED NATIONS. Food And Agriculture Organization of the United Nations Statistics Division. 2007. Disponível em:<http://www.faostat3.fao.org/download/P/PM/E > . Acesso em: 22 abr. 2007.

GOLDSTEIN, M.; KHAN, M. S. Income and price effects in foreign trade. In: JONES, R. W.; KENEN, P. B. (Ed.). Handbook of International Economics. Amsterdam: North Holland, 1985. v. II. p. 1041-1105.

. The Supply and demand for exports: a simultaneous approach. The Review of Economics and Statistics, v. 60, n. 2, p. 275-286, 1978.

GREENE, W. H. Econometric analysis. New Jersey: Prentice Hall, 2008.

GRUBEL, H. P.; LLOYD, P. J. Intra-industry trade: the theory and measurement of international trade in differentiated products. London: Mc Millan, 1975.

GUJARATI, D. Econometria Básica. 4. ed. São Paulo: Campus, 2006.

HIDALGO,A.B.Mudanças na estrutura do comércio internacional brasileiro: comércio interindústria x comércio intra-indústria. Análise Econômica, v. 11, p. 55-68, set. 1993.

JOHNSTON, J.; DINARDO, J. Métodos econométricos. 4. ed. Lisboa: McGraw-Hill, 2000.

LEAMER, E.; STERN, R. Quantitative international economics. Boston: Allyn and Bacon, 1970. (International Series in Economics).

MÓDOLO, D. B.; HIRATUKA, C. Impacto da concorrência chinesa em terceiros mercados: uma análise por regiões e por categorias tecnológicas. In: ENCONTRO NACIONAL DE ECONOMIA DA ANPEC, 40., 2012, Porto de Galinhas, PE. Anais... Porto de Galinhas, PE: ANPEC, 2012.

MORTATTI, C. M.; MIRANDA, S. H. G.; BACCHI, M. R. P. Determinantes do comércio BrasilChina de commodities e produtos industriais: uma aplicação VECM. Revista Economia Aplicada, V. 15, n. 2, p. 311-335. 2011.

PINTO, M. B. P. O crescimento das exportações brasileiras de manufaturados 1954-1974. Revista Estudos Econômicos, v. 10, n. 3, p. 101-143, 1980. 
RIOS, S. M. P. Exportações brasileiras de produtos manufaturados: uma avaliação econométrica para o período 1964/84. Revista Pesquisa e Planejamento Econômico, v. 17, n. 2, p. 299-332, 1987.

SAMPAIO, L. M. B.; SAMPAIO, Y.; COSTA, E. Mudanças políticas recentes e competitividade no mercado internacional de soja. Revista de Economia e Sociologia Rural, v. 44, n. 3, p. 383$411,2006$.

SILVA, A. D. B.;Um estudo das relações comerciais entre Brasil e China e da concorrência chinesa em terceiros mercados. 2011. 96 f. Dissertação. (Mestrado em Economia) do Programa de Pós-Graduação em Economia, Faculdade de Ciências Econômicas, Universidade Federal de Pernambuco, Recife, 2011.

SOUZA, S. S. et al. M. Mudanças cambiais e o efeito dos fatores de crescimento das receitas de exportações brasileiras de soja. Revista de Economia e Agronegócio, v. 5, n. 1, p. 1-24, 2007.

THORSTENSEN, V. et al. O Brasil frente a um mundo dividido em blocos. São Paulo: Nobel; Instituto Sul-Norte, 1994.

UNITED NATIONS. International Merchandise Trade Statistics.2013. Disponível em: http:// www.comtrade.un.org/monthly/Public/ReleaseInfo.aspx. Acesso em: 10 jan. 2013.

VASCONCELOS, C. R. F. O comércio Brasil-MERCOSUL na década de 90: uma análise pelas óticas da intensidade fatorial, comércio intra-indústria e criação e desvio de comércio.2000. 221 f. Tese (Doutorado em Economia) - Programa de Pós-Graduação em Economia, Faculdade de Ciências Econômicas, Universidade Federal de Pernambuco, Recife, 2000.

ZINI JR., A. A. Funções de exportação e de importação para o Brasil. Revista Pesquisa e Planejamento Econômico, v. 18, n. 3, p. 615-662, 1988.

Recebido em: 26/08/2013. Aceito em: 21/11/2013. 